\title{
Exploring the Intersectionality of Family SES and Gender with Psychosocial, Behavioural and Environmental Determinants of Physical Activity in Dutch Adolescents: A Cross-Sectional Study
}

André Mamede Soares Braga ( $\square$ mamedesoaresbraga@essb.eur.nl )

Erasmus University Rotterdam

Özcan Erdem

Municipality of Rotterdam

Gera Noordzij

Erasmus University College, Erasmus University

Inge Merkelbach

Erasmus University Rotterdam

Paul Kocken

Erasmus University Rotterdam

Semiha Denktas

Erasmus University Rotterdam

\section{Research Article}

Keywords: intersectionality, SES, psychosocial, environmental

Posted Date: September 24th, 2021

DOI: https://doi.org/10.21203/rs.3.rs-886324/v1

License: (c) (i) This work is licensed under a Creative Commons Attribution 4.0 International License.

Read Full License 


\section{Abstract}

\section{Background}

Examining the determinants of adolescent's physical activity (PA) and how they may differ according to the intersection of gender and family socioeconomic status (SES) can support the development of tailored interventions to more effectively promote adolescents' PA. This study explored how the influence of psychosocial, behavioural and environmental determinants on adolescent's PA differed according to gender and family SES.

\section{Methods}

This study used data from the Dutch survey Health Monitor Youth 2015. Adolescents $(n=9,068)$ aged 1219 were included for the study. The associations between psychosocial, behavioural, and environmental determinants and PA (days per week engaging in at least one hour of PA) were examined with multilevel linear regression analysis. Potential interactions between these determinants, gender and family SES were explored.

\section{Results}

On average, adolescents engaged in at least one hour of PA for 4,2 days per week. Poor self-perceived health, low peer social support, and a weak connection with the environment were all associated with lower PA in adolescents. Daily smoking, cannabis use, risk of problematic gaming and social media use, as well as lack of daily consumption of fruit, vegetables, water and breakfast were associated with lower PA, whereas binge drinking was not. Interactions revealed that poor self-perceived health was associated with lower PA in adolescents from moderate- and high-SES families, but not in low-SES adolescents, whereas cannabis use was only associated with lower PA amongst low-SES adolescents. Low peer social support was associated with lower PA across all groups, but it was most strongly associated with lower PA amongst male adolescents from low-SES families than in other subgroups. Amongst low-SES males, low peer social support was associated with a 1.47 reduction in days engaging in sufficient PA, compared with a 0.69 reduction for high-SES males.

\section{Conclusions}

This study identified several psychosocial, behavioural and environmental determinants that can be targeted to potentially increase adolescent's PA. We also found that correlates of PA differed according to the intersection of gender and family SES. Our findings suggest that PA interventions should be tailored according to gender and SES to address the specific needs, barriers and facilitators of different subgroups.

\section{Introduction}


Regular engagement in moderate-to-vigorous physical activity (MVPA) is associated with increased quality of life (1) and contributes to the prevention of a several severe health conditions, such as obesity $(2,3)$, cardiovascular disease $(3,4)$, cancer $(3,4)$ and depression $(5,6)$. Given that evidence suggests that adolescent physical activity (PA) tracks into young adulthood and influences life-long patterns of healthy behaviours (7), it is essential to ensure that adolescents are engaging in sufficient levels of PA. However, research suggests that less than half of the adolescents are adhering to the recommended levels of MVPA (i.e. one hour per day) in most western countries, such as in the USA (32.6\% of boys and $20.1 \%$ of girls), in Germany ( $20 \%$ of boys and $14 \%$ of girls) and in the Netherlands ( $22.3 \%$ of boys and $15.7 \%$ of girls). Additionally, evidence suggests that the compliance rate with recommended levels of MVPA is considerably lower for adolescents in families of low-socioeconomic status (SES) than for those of highSES (8). Remarkably, adolescents' levels of PA seem to be influenced by complex interactions of several factors, and, although evidence is scarce, a recent study suggests that the influence of these factors on PA may differ according to the adolescents' SES and sociodemographic characteristics (e.g. gender)(9). These findings highlight the necessity of not only identifying changeable determinants of adolescent PA in general, but also to investigate how these determinants differ between adolescents according to their socio-demographic and -economic characteristics.

Socio-ecological models of behaviour change suggest that health behaviours, such as PA, are influenced by the interaction of several factors at different levels $(10,11)$. At the individual level, relevant factors include various socio-demographic and -economic characteristics (e.g. gender, age, migration background, SES), as well as behavioural and psychosocial factors that have been identified as important determinants of PA. Research has shown that various socio-demographic and -economic characteristics, such as immigrant background, lower SES, female gender and older age in adolescents, were all predictors of lower levels of $\operatorname{PA}(8,12,13)$. Regarding behavioural determinants, other studies have found adolescent's levels of PA to not only be negatively associated with several health behaviours, such as lower fruit and vegetable consumption and cigarette smoking(14), but also to be negatively associated with excessive screen-time behaviours, such as problematic gaming (15) and social media use(16). Regarding psychosocial determinants of PA, poor self-perceived health status (17) has been associated with lower levels of PA in adolescents. Greater levels of social support from one's peers and family have all been consistently and strongly associated with increased levels of PA in adolescents(18, 19). Besides determinants at the individual-level, several determinants at the environmental-level that facilitate PA seem to influence adolescents' levels of PA, which include objective factors such as availability of recreational facilities (20), but also self-perceived factors such as aesthetics (20) and social ties with the neighbourhood (21). Remarkably, socio-ecological models propose not only that factors in multiple levels influence health behaviour, but also that these levels are interactive. For example, environmental determinants (e.g. safety) may influence people differently depending on their socio-demographic characteristics (e.g. gender), or on their unique set of values and motivations (10).

In addition to socio-ecological theories, several approaches have emerged in different fields emphasizing the need to explore interactions between socio-demographic characteristics in order to explain inequalities in healthy behaviours. One sociological approach that has recently been applied to 
epidemiological studies is intersectionality theory (22). Intersectionality theory posits that a person is shaped by their experiences as a whole. Thus, by dividing and addressing single categories of identity, key interactions between multiple characteristics of an individual's identity that create unique experiences may be overlooked.

Therefore, it may be essential to consider how determinants of PA may differ according these unique experiences that are largely shaped by the interplay of an individual's socio-demographic and -economic characteristics (e.g. gender, SES, ethnicity). For example, one study found that the positive effect of household income on PA was strong among ethnic minority men, moderate among white men and woman, but almost non-existent among ethnic minority woman (23). Similarly, the relative importance of certain psychosocial, behavioural and environmental determinants of PA may differ significantly between these subgroups. Intersectionality theory thus proposes that we should investigate how multiple sociodemographic and -economic characteristics (e.g. gender, SES, migration background) "intersect" or interact to influence the processes leading to healthy behaviours, rather than study the effect of these characteristics in isolation. Given that studies have shown that the determinants of adolescent's PA seems to vary according to gender $(9,24)$ and SES $(25)$, it is plausible that the influences of determinants on PA may depend on the unique interaction of adolescents' socio-demographic and -economic characteristics.

Although several studies have investigated the determinants of PA and its interaction with a certain sociodemographic characteristic in adults, few studies have explored whether the influence of relevant determinants of PA in adolescents differs according to the interplay of different socio-demographic and economic factors, such as gender and family SES. Examination of the potential influences of sociodemographic factors and their interactions with determinants of PA in adolescents could facilitate the development of more tailored PA interventions that address the unique needs of the individual. Therefore, in this explorative study we analysed data from a survey to identify determinants associated with adolescent's levels of PA and possible interactions with gender and family SES. We aimed to explore whether behavioural (e.g. smoking), psychosocial (i.e. self-perceived health and peer social support), and environmental determinants (i.e. connection with neighbourhood) independently predict adolescents' levels of PA. Additionally, this study explores whether the influences of these determinants on PA varied by gender and family SES, which have been identified as the most relevant socio-demographic and economic factors for PA $(24,26,27)$. We expect to find associations between levels of PA in adolescents and the determinants selected based on the literature $(14,15,21,28)$. Additionally, we hypothesize that the associations between determinants and adolescents' PA will vary according to gender and family SES, seeing as the intersection of these socio-demographic and -economic characteristics constitutes significantly different groups and identities.

\section{Methods}

\section{Survey Design and Population}


The present study concerns a secondary analysis utilizing the data from the cross-sectional survey Health Monitor Youth 2015 (Gezondheidsmonitor Jeugd 2015 GGD'en en RIVM) conducted by the Municipal Health Services of Rotterdam in the Netherlands (29). This survey was conducted to assess the mental and physical health of adolescents (aged 12-19 years), and to gain insight into the determinants of health behaviours in this population. This survey was administered in Rotterdam, the second largest city of The Netherlands, and in 14 smaller surrounding municipalities. A total of 50 secondary schools participated in this survey, corresponding to approximately $39 \%$ of the secondary school population. Data was collected in the classroom on a voluntary basis among students in grades 2 and 4 (equivalent to grades 8 and 10 in the United States) in the fall of 2015. Parents received written information on the survey and could object to their child's participation. In total 9,136 adolescents participated in the study. The response rate was $76 \%$. For the analyses we included adolescents $(n=9,068)$ who filled out the key variables (gender, age, migration background, educational level, family SES, municipality and physical activity). This study relies on secondary analysis of anonymized data and is therefore exempt from ethical approval.

\section{Measures}

The survey combined validated questionnaires and scales jointly developed for the Health Monitor Survey Youth by all municipal health services in the Netherlands in collaboration with the National Institute for Public Health and the Environment. Unless otherwise specified, the scales and cut-off points used were jointly designed and tested The questionnaires developed for this survey have been continuously tested and improved, and these scales have now been widely used in other research based on data from the Health Monitor Survey Youth $(30,31)$. All the questionnaires were administered in Dutch.

\section{Outcome measure}

Physical activity was assessed with one-item from the PACE + questionnaire (32), namely "How many days per week do you do sports or physical exercise for at least 1 hour?". This item was scored on an 8point Likert scale, ranging from "(0) (Almost) never" to "(7) Everyday". The PACE + questionnaire has been previously shown to have acceptable test-retest reliability and criterion validity for assessing adolescent's non-achievement of MVPA recommendations $(32,33)$.

\section{Socio-demographic measures}

Demographics characteristics measured included gender $(\mathrm{m} / \mathrm{f})$, age (year of birth), migration background and educational level. Migration background was determined by asking the birth place of adolescents and their parents, and participants were categorized as either native Dutch (i.e. both parents and the adolescent were born in the Netherlands), Western immigrants (i.e. the adolescent, or one or both parents were born in a Western country) or non-Western immigrants (i.e. the adolescent, or one or both parents were born in a non-Western country). Educational level was measured by asking participants to indicate their current educational level (i.e. basic or theoretical pre-vocational secondary education, secondary education, pre-university education). 


\section{Family SES}

Perceived financial difficulties were used as an indicator of family SES and were measured with the following item developed "Do you have difficulties to make ends meet at home with regards to money? (by home we mean the family that you live with most of the time)" rated on a 4-point Likert scale. Answering options included "No, we do not have difficulties at all", "No, we do not have difficulties but we must be careful with our spending", "Yes, we have some difficulties" and "Yes, we have a lot of difficulties". Family SES was categorized as High if they answered "No, we do not have difficulties at all", Moderate if they answered "'No, we do not have difficulties but we must be careful with our spending", and Low if they answered either "Yes, we have some difficulties" or "Yes, we have a lot of difficulties".

\section{Behavioural determinants}

Food and Water intake was assessed through multiple variables related to eating and drinking behaviour. To measure daily fruit and breakfast consumption, single-item questions from previous research assessing these eating behaviours in adolescents in the Netherlands were used (34). Daily fruit consumption was assessed with the item "On how many days per week do you eat fruit?" and daily breakfast consumption was assessed with the item "On how many days per week do you eat breakfast?", both which were rated on an 8-point Likert scale indicating the number of days ranging from "(Almost) never" to "Every day". Based on these items, two additional single-item questions were developed for the Health Monitor Survey to measure daily vegetable consumption and daily water drinking. Daily vegetable consumption was assessed with the item "On how many days per week do you eat vegetables?" and daily water drinking was assessed with the item "On how many days per week do you drink one or more glasses of water?", which were similarly rated on an 8-point Likert ranging from "(0) (Almost) never" to "(7) Every day". Daily food and water intake variables were dichotomized as Yes (i.e. participants who answered Every day) and No (i.e. participants who reported consumption on six days or less).

Excessive screen time behaviours were assessed by measuring problematic social media use and problematic gaming. The items used were adapted from the validated Compulsive Internet Use Scale (35) and the Gaming Addiction Scale (36). Problematic social media use was assessed with six items, such as "How often do you find it difficult to stop using social media?" or "How often do you feel restless, stressed, or irritated when you cannot use social media?". Problematic gaming was similarly assessed with six items, such as "How often do you find it difficult to stop gaming?" or "How often do you prefer to game than to spend time with others (e.g. with your friends or your parents)?". Items were scored on a 5point Likert scale ranging from "(1) Never" to "(5) Very often". For both variables, participants' responses to the six items were averaged, and participants whose average score was higher than two were categorized as having a risk for problematic gaming. Participants were also categorized as not having a significant risk for problematic gaming or social media use if they answered "(Almost) Never " to the precursor items: "How often do you game?" or "How often are you active on social media?". Problematic gaming and social media use scales were developed by IVO, an institute responsible for researching problematic internet use and health behaviours in youth in the Netherlands (37). 
Early use of drugs and alcohol was assessed through several items measuring the frequency of consumption of common soft drugs. Daily smoking was assessed by asking adolescents who indicated having smoked before to answer the item "How often do you smoke now" rated on a 4-point Likert scale with the following answering options: "I do not smoke", "Less than one time per week", "At least once per week, but not every day" "Every day". Since we were interested in identifying clinically significant unhealthy behaviours as risk factors, daily smoking consumption was dichotomized as Yes (i.e. participants who reported smoking every day) and No (i.e. non-smokers and nondaily smokers) in order to distinguish between occasional smokers and heavy daily smokers. Binge drinking was assessed with the item "How often in the last 4 weeks did you consume five or more alcoholic drinks in one occasion (for example at a party on one evening?)". The item was rated on 7-point Likert scale ranging from "Never" to "9 times or more", and participants were categorized as binge drinkers if they answered any option other than "Never", which would indicate at least one instance of binge drinking behaviour in the last four weeks. Cannabis use was assessed with the item "On how many days in the last four weeks did you consume weed (marijuana) or hash?", which was rated on a 7-point Likert scale ranging from "Never" to "30 days or more". Adolescents who indicated using cannabis in the previous four weeks were considered as cannabis users.

\section{Psychosocial determinants}

Self-perceived health was assessed with the validated single-question item "How is your health in general? "(38), which was rated on a 5-point Likert scale ranging from "(1) Very bad" to "(5) Very good". This measure has been demonstrated to have predictive validity for several health outcomes, including all-cause mortality (39). This variable was dichotomized into poor (i.e. "fair", "bad", and "very bad") and good (i.e. "very good" and "good") health, with good serving as the reference category.

Peer social support was assessed with six items from the validated European KIDSCREEN-52 healthrelated quality of life $(\mathrm{HRQoL})$ questionnaire $(40,41)$ inquiring about their social experiences in the previous week. Examples of items used included: "Have you spent time with your friends?" or "Do you have friends who you can trust?". Items were rated on a 5-point Likert scale indicating the frequency the behaviour/feelings in the statements ("Never", "Seldom", "Sometimes", "Often" and "Always"). Based on the procedure of studies assessing the psychometric properties of KIDSCREEN-52, Rasch scores were computed for the Social Support and Peers variable and transformed into T-values, with a scale mean of 50 and a standard deviation of 10 , with higher values indicating greater levels of social support. Subsequently, following the recommended thresholds for scoring KIDSCREEN-52 scales (42), the Peer Social Support variable was dichotomized as low when T-values were more than half a standard deviation below the mean (i.e. T-values $<45$ ) or moderate-to-strong when T-values were not lower than half a standard deviation below the mean (i.e. T-values $\geq 45$ ).

\section{Environmental determinants}

Connection with neighbourhood was assessed through three items, namely "I would like to move from my neighbourhood", "If I were to move, I would really miss my neighbourhood" and "I think that I live in a 
great neighbourhood", anchored on a 5-point Likert scale ranging from "(1) Strongly agree" to "(5) Strongly disagree". After reversing the scores of the first item, a total score was calculated by averaging summing these three items, and this variable was subsequently dichotomized into weak connection with neighbourhood (i.e. a total score higher than 3.5) or strong-to-moderate connection with neighbourhood (i.e. a total score lower than 3.5).

\section{Statistical Analysis}

We analysed the descriptive characteristics of our study population stratified by gender (Table 1). In this study, observations of adolescents' levels of PA (level 1) were nested within different schools (level 2), which in turn were nested in different municipalities (level 3). For that reason, we utilized multilevel linear models to account for the nested hierarchical structure of our data by including a random intercept in our model for the different levels when the variance at that level was significantly different from zero. Given that variance at the municipality level was not significant $(p>0.05)$, whereas variance at the school-level was significant $(p<0.05)$, a random intercept was included to adjust for the clustering effects of observations within the same school. The intraclass correlation coefficient (ICC) in the null model showed that $3.6 \%$ of the variation within adolescents' PA is attributable to differences between the schools. 
Table 1

Descriptive statistics of the study population stratified by gender $(n=9.138)$

Total

Mean Min-

(S.D.) Max
Males

Mean

(S.D.)
Females

Mean

(S.D.)

Outcome variable

Physical activity

Number of days per week engaging in at least one hour of physical activity

$$
4,2(2,1) \quad(0-7) \quad 4,4(2,0) \quad 3,9(2,1)
$$

Family SES

\begin{tabular}{|lllll|}
\hline Low & 730 & 8.1 & 7.1 & 9.0 \\
\hline Middle & 2861 & 31.6 & 28.9 & 34.3 \\
\hline Socio-demographic characteristics & 5477 & 60.4 & 64.0 & 56.7 \\
\hline Gender & & & & \\
\hline Males & & & & \\
\hline Females & 4577 & 50.5 & 100.0 & \\
\hline Age & 4491 & 49.5 & & 100.0 \\
\hline$\leq 13$ years & & & & \\
\hline 14 years & 3321 & 36.6 & 34.8 & 38.5 \\
\hline 15 years & 1591 & 17.5 & 18.6 & 16.5 \\
\hline$\geq 16$ years & 2420 & 26.7 & 25.4 & 28.0 \\
\hline Migration background & 1736 & 19.1 & 21.3 & 17.0 \\
\hline Non-Western immigrants & & & & \\
\hline Western immigrants & 3030 & 33.4 & 33.4 & 33.4 \\
\hline Native Dutch & 677 & 7.5 & 7.8 & 7.1 \\
\hline Educational level & 5361 & 59.1 & 58.8 & 59.5 \\
\hline Basic pre-vocational secondary education & & & & \\
\hline Theoretical pre-vocational secondary education & 2757 & 30.4 & 29.9 & 30.9 \\
\hline Secondary education & 1541 & 17.0 & 17.0 & 17.0 \\
\hline
\end{tabular}




\begin{tabular}{|c|c|c|c|c|}
\hline & Total & & Males & Females \\
\hline Pre-university education & 1753 & 19.3 & 18.9 & 19.8 \\
\hline \multicolumn{5}{|l|}{ Municipality } \\
\hline Rotterdam & 3339 & 36,8 & 36,3 & 37,4 \\
\hline Surrounding municipalities & 5729 & 63,2 & 63,7 & 62,6 \\
\hline \multicolumn{5}{|l|}{ Behavioural determinants } \\
\hline \multicolumn{5}{|c|}{ Risk of problematic social media use } \\
\hline No or very little risk & 7761 & 87.0 & 92.0 & 82.0 \\
\hline High risk & 1156 & 13.0 & 8.0 & 18.0 \\
\hline \multicolumn{5}{|l|}{ Risk of problematic gaming } \\
\hline No or very little risk & 8299 & 93.3 & 88.4 & 98.2 \\
\hline High risk & 597 & 6.7 & 11.6 & 1.8 \\
\hline \multicolumn{5}{|l|}{ Daily smoking } \\
\hline No & 8665 & 95.6 & 96.1 & 95.1 \\
\hline Yes & 398 & 4.4 & 3.9 & 4.9 \\
\hline \multicolumn{5}{|c|}{ Cannabis use in the last 4 weeks } \\
\hline No & 8640 & 95.4 & 94.0 & 96.8 \\
\hline Yes & 417 & 4.6 & 6.0 & 3.2 \\
\hline \multicolumn{5}{|l|}{ Binge drinker } \\
\hline No & 7652 & 84.4 & 84.3 & 84.6 \\
\hline Yes & 1409 & 15.6 & 15.7 & 15.4 \\
\hline \multicolumn{5}{|l|}{ Daily breakfast consumption } \\
\hline Yes & 6161 & 68.0 & 72.4 & 63.4 \\
\hline No & 2903 & 32.0 & 27.6 & 36.6 \\
\hline \multicolumn{5}{|l|}{ Daily fruit consumption } \\
\hline Yes & 2783 & 30.7 & 28.9 & 32.5 \\
\hline No & 6279 & 69.3 & 71.1 & 67.5 \\
\hline \multicolumn{5}{|l|}{ Daily vegetable consumption } \\
\hline Yes & 3672 & 40.5 & 37.6 & 43.5 \\
\hline
\end{tabular}




\begin{tabular}{|c|c|c|c|c|}
\hline & Total & & Males & Females \\
\hline No & 5393 & 59.5 & 62.4 & 56.5 \\
\hline \multicolumn{5}{|l|}{ Daily water drinking } \\
\hline Yes & 5678 & 62.6 & 62.1 & 63.1 \\
\hline No & 3390 & 37.4 & 37.9 & 36.9 \\
\hline \multicolumn{5}{|l|}{ Psychosocial determinants } \\
\hline \multicolumn{5}{|l|}{ Peer social support } \\
\hline High score on social support & 8289 & 92.0 & 90.3 & 93.6 \\
\hline Low score on social support & 725 & 8.0 & 9.7 & 6.4 \\
\hline \multicolumn{5}{|l|}{ Self-perceived health } \\
\hline Good or very good & 8040 & 88.7 & 91.1 & 86.3 \\
\hline Bad or very bad & 1024 & 11.3 & 8.9 & 13.7 \\
\hline \multicolumn{5}{|l|}{ Environmental determinants } \\
\hline \multicolumn{5}{|l|}{ Connection with the neighbourhood } \\
\hline Strong connection with the neighbourhood & 7878 & 88.6 & 89.2 & 87.9 \\
\hline Weak connection with the neighbourhood & 1018 & 11.4 & 10.8 & 12.1 \\
\hline
\end{tabular}

We firstly investigated the relationship between different socio-demographic characteristics (i.e. gender, age, migration background, educational level, municipality), family SES and levels of PA (Table 2). Subsequently, we separately examined the relationships between psychosocial, behavioural and environmental determinants and levels of PA, while controlling for the effects of socio-demographics characteristics (i.e. gender, age, migration background, educational level, municipality) and family SES (Table 3). Additionally, given that literature suggests that determinants or correlates of PA may differ by gender $(9,24)$ and SES $(25,43)$, we tested for possible two-way interactions between the psychosocial, behavioural and environmental determinants and family SES. If two-way interaction term was statistically significant, a figure is presented to visualize the interaction by depicting the predicted fixed PA scores (Figs. 1 and 2) and the associations are included in the text. Subsequently, we also tested for possible three-way interactions between the psychosocial, behavioural and environmental determinants, family SES and gender. If three-way interaction term was statistically significant, we presented the associations in a table (Table 4). All analyses were performed in SPSS 25 . Results were considered to be statistically significant at $p<0.05$. 
Table 2

- The associations between socio-demographic characteristics, family SES and levels of PA

\begin{tabular}{|c|c|c|c|}
\hline \multirow{2}{*}{ Intercept } & \multirow{2}{*}{$\begin{array}{l}B^{*} \\
5.25\end{array}$} & \multicolumn{2}{|c|}{$(95 \% \mathrm{Cl})$} \\
\hline & & 5.05 & 5.46 \\
\hline \multicolumn{4}{|l|}{ Family SES } \\
\hline Low & -0.32 & -0.47 & -0.16 \\
\hline Medium & -0.14 & -0.23 & -0.05 \\
\hline High & ref. & & \\
\hline \multicolumn{4}{|l|}{ Gender } \\
\hline Females & -0.50 & -0.58 & -0.41 \\
\hline Males & ref. & & \\
\hline \multicolumn{4}{|l|}{ Age } \\
\hline$\leq 13$ years & 0.37 & 0.25 & 0.49 \\
\hline 14 years & 0.33 & 0.19 & 0.47 \\
\hline 15 years & 0.18 & 0.06 & 0.31 \\
\hline$\geq 16$ years & ref. & & \\
\hline \multicolumn{4}{|l|}{ Migration background } \\
\hline Non-Western immigrants & -0.39 & -0.49 & -0.29 \\
\hline Western immigrants & -0.25 & -0.41 & -0.08 \\
\hline Native Dutch & ref. & & \\
\hline \multicolumn{4}{|l|}{ Educational level } \\
\hline Basic pre-vocational secondary education & -0.64 & -0.81 & -0.48 \\
\hline Theoretical pre-vocational secondary education & -0.44 & -0.59 & -0.28 \\
\hline Secondary education & -0.16 & -0.31 & 0.01 \\
\hline Pre-university education & ref. & & \\
\hline \multicolumn{4}{|l|}{ Municipality } \\
\hline Rotterdam & -0.06 & -0.17 & 0.05 \\
\hline Other municipalities & ref. & & \\
\hline * Bold beta indicates statistical difference in mea & refere & catego & $<0.05)$ \\
\hline
\end{tabular}




\section{Study Population}

Table 1 shows the descriptive statistics of our study population stratified by gender.

\section{The associations of family SES and socio-demographic characteristics with PA in adolescents}

Multilevel linear regression analysis showed that female gender, older age, lower levels of education and low family SES were all associated with lower levels of PA (Table 2). Additionally, native Dutch adolescents moved significantly more than both adolescents with Western immigrant and non-Western immigrant backgrounds, with non-Western immigrant background being associated with the lowest levels of PA.

\section{Behavioural, Psychosocial and Environmental determinants and levels of PA in adolescents}

Regarding behavioural determinants, multilevel linear regression analysis demonstrated that problematic social media use, problematic gaming, daily smoking, and cannabis use in the previous four weeks were all significant predictors of lower levels of PA in adolescents (Table 3). Conversely, our findings showed that daily water drinking, as well as daily breakfast, fruit and vegetable consumption, were all significant predictors of higher levels of PA in adolescents. Additionally, with respect to psychosocial determinants, poor self-perceived health and lower levels of peer social support were significantly associated with lower levels of PA in adolescents. With regards to environmental determinants, weaker bond with neighbourhood was associated with decreased PA. 
Table 3

- The associations of psychosocial, behavioural and environmental determinants with PA in adolescents**

\begin{tabular}{|c|c|c|c|c|}
\hline & & $B^{*}$ & $95 \% \mathrm{C}$ & \\
\hline Behavioura & determinants & & & \\
\hline Model 1 & Lack of daily fruit consumption (ref. = daily consumption) & -0.48 & -0.57 & -0.39 \\
\hline Model 2 & Lack of daily vegetable consumption (ref. = daily consumption) & -0.33 & -0.43 & -0.25 \\
\hline Model 3 & Lack of daily water drinking (ref. = daily consumption) & -0.44 & -0.53 & -0.35 \\
\hline Model 4 & Lack of daily breakfast consumption (ref. = daily consumption) & -0.33 & -0.42 & -0.24 \\
\hline Model 5 & Risk of problematic social media use (ref. = no risk) & -0.34 & -0.46 & -0.21 \\
\hline Model 6 & Risk of problematic gaming (ref. = no risk) & -0.53 & -0.69 & -0.35 \\
\hline Model 7 & Daily smoking (ref. = not smoker) & -0.31 & -0.52 & -0.11 \\
\hline Model 8 & Cannabis use in the last 4 weeks (ref. = no use) & -0.21 & -0.41 & -0.01 \\
\hline Model 9 & Binge drinking (ref. = no binge drinking) & 0.03 & -0.09 & 0.15 \\
\hline Psychosoc & al determinants & & & \\
\hline Model 10 & Poor self-perceived health (ref. = good) & -0.50 & -0.63 & -0.37 \\
\hline Model 11 & Low peer social support (ref. = high) & -0.71 & -0.86 & -0.56 \\
\hline Environme & tal determinants & & & \\
\hline Model 12 & Weak connection with the neighbourhood (ref. = strong) & -0.21 & -0.35 & -0.08 \\
\hline * Bold betc & dicates statistical difference in mean $P A$ relative to reference $c$ & gory ( & (0.05). & \\
\hline
\end{tabular}

\section{Exploring the interactions between Family SES, gender and determinants of PA}

Our results indicate that the influence of certain determinants on adolescent's PA varies according to gender and/or family SES, as evidenced by two-way and three-way interactions detected in our models.

Cannabis. A two-way interaction revealed that the influence of cannabis use was significantly different for adolescents with different levels of family SES. Namely, as shown in Fig. 1, cannabis use in the last four weeks was only significantly associated with lower PA for adolescents from low-SES families $(B=$ 
$-0.72,95 \% \mathrm{Cl}[-1.30,-0.14])$, but not for those from moderate $(B=-0.31,95 \% \mathrm{Cl}[-0.68,0.06])$ and high $(B=$ $-0.03,95 \% \mathrm{Cl}[-0.29,0.24])$ SES families. No significant three-way interaction between gender, family SES and cannabis use was observed.

Perceived Health. A two-way interaction revealed that the influence of self-perceived health was significantly different for adolescents with different levels of family SES. As shown in Fig. 2, poor selfperceived health was only associated with lower levels of PA for adolescents from high- $(p<0.05, B=$ $-0.57,95 \% \mathrm{Cl}[-0.76,-0.37])$ and moderate- $(p<0.05, B=-0.62,95 \% \mathrm{Cl}[-0.83,-0.40])$ SES families, but not for adolescents from low-SES families $(p>0.05, B=-0.12,95 \% \mathrm{Cl}[-0.48,0.23])$. No significant three-way interaction between gender, family SES and self-perceived health was observed.

Peer social support. A two-way interaction (not shown) suggested that low peer social support seemed to have a stronger effect on PA of adolescents from low- or moderate-SES families than for adolescents from high-SES families, although this difference did not reach statistical significance $(p=0.11, t=1.59$, $95 \% \mathrm{Cl}[-0.04,0.38])$. Subsequently, given that the interaction between gender and family SES may shape adolescent's PA experiences, we tested for three-way interactions to explore whether the effects of peer social support also varied as a function of adolescent's gender and family SES. The analysis revealed a borderline significant three-way interaction between peer social support, family SES and gender $(p=$ $0.052, t=1.94,95 \% \mathrm{Cl}[-0.01,0.20])$. Table 4 shows the associations between peer social support and levels of PA in adolescents stratified by family SES and gender. Low peer social support had a stronger negative association with PA amongst male adolescents from low-SES families, compared to females. Amongst low-SES males, low peer social support was associated with a 1.47 reduction in days engaging in sufficient PA, compared with 0.69 reduction for males from high-SES families, and with a 0.8 days reduction for females from low-SES families.

Table 4

- The associations between peer social support and levels of PA in adolescents stratified by family SES and gender**

\begin{tabular}{|c|c|c|c|c|c|}
\hline Family SES & Gender & Social Support & $B^{*}$ & \multicolumn{2}{|c|}{$(95 \% \mathrm{Cl})$} \\
\hline \multirow[t]{2}{*}{ Low } & Males & Low social support (ref. = high) & -1.47 & -2.05 & -0.90 \\
\hline & Females & Low social support (ref. = high) & -0.80 & -1.47 & -0.14 \\
\hline \multirow[t]{2}{*}{ Moderate } & Males & Low social support (ref. = high) & -0.85 & -1.19 & -0.52 \\
\hline & Females & Low social support (ref. = high) & -0.42 & -0.81 & -0.03 \\
\hline \multirow[t]{2}{*}{ High } & Males & Low social support (ref. = high) & -0.69 & -0.95 & -0.44 \\
\hline & Females & Low social support (ref. = high) & -0.52 & -0.88 & -0.15 \\
\hline \multicolumn{6}{|c|}{ * Bold beta indicates statistical difference in mean PA relative to reference category $(p<0.05)$} \\
\hline \multicolumn{6}{|c|}{ ** Model adjusted for age, migration background, educational level and municipality. } \\
\hline
\end{tabular}




\section{Discussion}

This study explored socio-demographic, socioeconomic, behavioural, psychosocial, and environmental determinants of adolescent PA and examined whether the determinants of PA varied according to the intersection of gender and family SES.

Our findings for socio-demographic and -economic determinants revealed that female gender, older age, lower family SES, lower educational levels and immigrant backgrounds were all associated with lower PA. These results support previous findings linking lower PA in adolescents to female gender, older age, immigrant backgrounds, lower family SES and lower education $(8,12,26,43)$. Several mechanisms could explain these associations. For example, research shows that self-efficacy and social support for PA are key mediators of the relationships between PA and both income and educational level (43). Similarly, gender discrepancies in PA can be partially attributed to motivation. A recent study found that body image was a more important motivation for regular PA for female adolescents than males, whereas the fun of physical exertion was a primary motivation for PA in more males than females (24). Female adolescents also seem less inclined to engage in recreational PA with peers after school, such as in organized sports clubs, largely accounting for PA gender differences (44).

Amongst behavioural determinants, daily smoking, cannabis use, risk of problematic gaming and social media use, as well as lack of daily consumption of fruit, vegetables, water and breakfast were all associated with lower PA. These findings are in line with the evidence that adolescent PA are associated with other health behaviours, such as smoking (14), and that motivational and self-regulatory processes leading to engagement in one's health behaviour may "spill-over" into another $(45,46)$. Such psychosocial factors are also likely confounders, given that higher self-efficacy, social support or self-regulatory capacity are all related to increased PA (47-50), but also predict, for example, greater vegetable consumptions $(48,51)$ or less smoking $(52,53)$. Our findings support the evidence linking problematic social media use or gaming to decreased PA $(15,16)$. Although confounding variables could partially explain this association, problematic social media use and gaming may have a more direct negative effect on PA, since they can increase sedentary behaviour and substitute PA in the adolescent's routine (54-56).

For psychosocial determinants, poorer self-perceived health, low peer social support and weak connection with the neighbourhood were associated with lower PA. In line with the evidence from a systematic review (57), our findings revealed that poor self-perceived health was associated with lower PA in adolescents. This study also found that peer social support was strongly associated to PA, which is consistent with evidence that peer social support is one of the most important predictors of adolescent's PA (58).

Finally, for environmental determinants a weak connection with the neighbourhood was associated with lower PA, which is consistent with studies demonstrating a relationship between a neighbourhood's social environment and adolescent PA $(21,59,60)$. The strong social ties in one's neighbourhood may influence adolescent's PA through several stress-buffering, health-enhancing mechanisms, such as social norms, social support, self-efficacy, self-control, and increased contact with others $(61,62)$. 
Although several similar epidemiological studies have explored determinants of PA in adolescents, few studies have explored how these determinants may vary according to the interplay of certain sociodemographic and -economic characteristics. Intersectionality theory emphasizes that people's resources, experiences and identities are not only shaped by several individual characteristics, such as gender and SES, but also by the unique interplay of these characteristics (63). From the lens of intersectionality, low SES and female gender are associated with vulnerabilities for lower PA which may not be separate, but rather interactive and multiplicative in their effects (64). Our findings indicated that the effects of certain determinants on PA was influenced by the intersection of gender and family SES, which may reflect the unique needs and barriers for PA in subgroups with compounding vulnerabilities.

While most behaviours were consistently related to PA across gender or family SES in our sample, our findings showed that cannabis use was only associated with less PA amongst adolescents from lowSES. This may reflect the role of possible confounders, such as low self-control or low parental social support, which may render adolescents with low-SES more vulnerable to both early cannabis use and low levels of PA $(19,53,65-68)$. Future research is needed to examine the causality of the relationship between early cannabis use and adolescent PA, while accounting for the role of potential confounders.

Furthermore, in our sample, poor perceived health was associated with decreased levels of PA in adolescents from moderate- or high-SES families, but not for adolescents from low-SES families. One possible explanation for this finding is that adolescents from low-SES households may have different conceptions of health, in which PA may be less strongly linked to health perceptions. In support of this notion, research has demonstrated that associations with self-perceived health were considerably different between native Dutch individuals and ethnic minorities (69), who are typically of lower SES (70). These findings suggest that the meaning attached to the single-item question assessing self-perceived health may differ between ethnic and SES groups.

Our findings also revealed that, while peer social support was a significant predictor of PA in all groups, it exerted the strongest effects on the PA of male adolescents from low-SES families, suggesting that peer social support may be particularly important for this subgroup. Research has found that children from high/middle SES schools report engaging in more family-based activities and organized sports than adolescents from low-SES schools (71). In contrast, since costs are an important barrier for PA in adolescents from low-SES schools, this group reports engaging in more unstructured "free-play", which is more influenced by peer social support (71). Another study has shown that parental social support, an important predictor of adolescents' PA (19), is lower in low-SES adolescents than in high-SES adolescents (72). Given that other forms of social support for PA may be lacking in their home environment and that there are limited opportunities for family-based activities or organized sports, peer social support may be particularly important for promoting PA in adolescents from low-SES families.

Importantly, the three-way interaction with family SES and gender also suggested that, amongst adolescents from low-SES families, peer social support was also more important for males than females. This finding is in line with another study showing that peer social support was an important determinant 
of PA in male adolescents, but not in females (28). These results may reflect previously discussed gender differences in motivation for PA. Given that fun of PA is a more prevalent motivation for PA in males than in females (24), and the fact that male adolescents are more likely to join sport clubs (44), it is plausible that peer social support has a stronger influence on the PA of male adolescents than females. The idea of "pick-up" games or neighbourhood activities may be more prevalent among males than females, and such activities may be more influenced by the social support of peers. Certain environmental factors, such as neighbourhood safety, may also limit the opportunities for outside play for females' adolescents more than for males, particularly for those from low-SES families (73).

These findings emphasize the importance of exploring the intersections of socio-demographic and economic factors when exploring the determinants of adolescents PA, since the interaction of these characteristics may give rise to unique experiences with different needs, barriers and facilitators for PA. By investigating intersectionality, public health professionals can develop more specific recommendations and interventions to promote adolescent's PA based, for instance, on the interplay of gender and SES.

The strengths of this study included high participation rates and the systematic recruitment of a large sample of male and female adolescents from secondary schools, which ensured that our sample was representative of this target group and that our results can be generalized to other similar populations. Additionally, rather than exclusively focusing on cognitive factors typically researched in the context of PA, this study assessed correlates of PA from various domains, namely socio-demographic and economic characteristics, psychosocial, behavioural and environmental determinants. Our results indicate that relevant determinants from these different domains are not completely independent, but rather "intersect" or interact with each other. Focusing exclusively on a single domain and overlooking important determinants of PA at different levels (e.g. sociodemographic or environmental) may thus lead to inaccurate conclusions. Therefore, the findings on this study emphasizes the need of a multivariate approach to understanding of factors associated with adolescent's PA, as well as of how these determinants may vary according to socio-demographic and -economic characteristics. As suggested by intersectionality theory, gaining insight on how the influence of certain determinants on PA may vary, for instance, according to the adolescent's gender or SES, can guide the tailoring of future interventions to address the specific needs of individuals.

Nevertheless, several limitations of the current study should be considered when interpreting the results. It is important to note that this study adopted a cross-sectional study design, thus causality cannot be inferred for the associations observed. Longitudinal study designs are needed to further examine the link between sociodemographic characteristics, determinants of PA, and adolescent's PA in order to gain more insight into the causality of these relationships. This was an explorative study in which the effect of multiple potential determinants of PA and their interactions with socio-demographic and -economic factors (i.e. gender and family SES) were investigated. Hence, although the variables included were carefully selected by behavioural experts as potential predictors of adolescent's PA prior to the start of the study, we recognize that multiple comparisons may have enhanced the chance of a type 1 error, which is 
a limitation of this study. Nonetheless, this explorative designed allowed us to explore potential differences in determinants of PA according to the intersection of gender and family SES, rather than examining these factors in isolation, which is an approach that has largely been overlooked. To guide the development of tailored PA interventions, further research is needed to replicate our findings and to continue investigating how the intersection of socio-demographic and -economic characteristics influences determinants of PA in adolescents.

Another limitation inherent to research based on population surveys was the use of self-report measures of PA. Although the survey incorporated a widely used and validated PA measure $(32,33)$, it is well established that self-report measures of PA are limited by recall difficulties, social desirability bias, and overestimation of PA levels, especially in adolescents $(74,75)$. Moreover, the single-item measure used assessed total levels of PA, which limited our ability to explore predictors of active-transport, recreational, and school-based PA separately. Future studies should collect data separately on these types of PA in order to explore the differential effects of various factors on certain types of PA. Despite the limitations of the self-report measures used, the current study was not only able to identify several determinants that are associated with total PA in adolescents, but also to gain insight on how the influence of these determinants vary according the intersection of gender and family SES.

\section{Conclusion}

This study identified several factors that were associated with lower levels PA in adolescents. Moreover, we found that the influence of certain determinants on PA differed according to the intersection of gender and family SES. For example, peer social support was the strongest determinant of adolescents' PA in our sample, but it had a stronger correlation with the PA of male adolescents from low-SES families than of any other subgroups. Therefore, our findings suggest that PA interventions in adolescents may need to target different factors according to the adolescent's gender and family SES in order to address the specific barriers and facilitators of PA in these subgroups. Future studies are needed to investigate how socio- demographic and -economic characteristics (e.g. gender, SES, migration background) can intersect and uniquely shape adolescent's PA experiences, as well as to explore how the determinants of PA may vary for different subgroups according to these experiences.

\section{Abbreviations}

PA: Physical Activity;

SES: Socioeconomic Status

\section{Declarations}

\section{Author contributions}


AM led the writing of the manuscript, under the supervision of the ÖE, IM, PK, GN and SD. ÖE performed the statistical analysis of the data. AM, ÖE, IM and PK were involved in the conception, design and planning of the study, as well as in the interpretation of the data, under the supervision of GN and SD. GN and SD were involved I the general supervision of the study, and helped to write and critically revise the manuscript. All authors read and approved the final manuscript.

\section{Funding}

No funding was specifically acquired for this research.

\section{Availability of data and materials}

The complete datasets supporting the conclusion of this article are not publicly available in an online repository, but can be made available upon request. Requests should be directed at the municipal health services (monitorgezondheid@ggdghor.nl).

\section{Ethical approval and consent to participate}

This study was conducted in accordance with the Declaration of Helsinki. Under Dutch law, an ethical review is not necessary for the secondary analysis of anonymized data collected through the national health survey. Formal consent is not required for this type of study.

\section{Consent for publication}

Not applicable.

\section{Competing interest}

The authors declare no competing interests.

\section{Acknowledgments}

The authors would like to thank Gea Schouten for her contribution in data collection.

\section{References}

1. Wu XY, Han LH, Zhang JH, Luo S, Hu JW, Sun K. The influence of physical activity, sedentary behavior on health-related quality of life among the general population of children and adolescents : A systematic review. PLoS One. 2017;12(11):1-29.

2. Kelly J, Reilly JJ, Jime D. Associations between objectively measured habitual physical activity and adiposity in children and adolescents: Systematic review. Int J Pediatr Obes. 2010;5(April 2009).

3. Warburton DER, Nicol CW, Bredin SSD. Health benefits of physical activity: the evidence. CMAJ. 2006;174(6). 
4. Lacombe J, Armstrong MEG, Wright FL, Foster C. The impact of physical activity and an additional behavioural risk factor on cardiovascular disease, cancer and all-cause mortality : a systematic review. BMC Public Health. 2019;

5. Biddle SJH, Asare M. Physical activity and mental health in children and adolescents: a review of reviews. Br J Sport Med. 2020;45.

6. Teychenne M, Ball K, Salmon J. Physical activity and likelihood of depression in adults: A review. Prev Med (Baltim). 2008;46:397-411.

7. Hayes G, Dowd KP, Ph D, Macdonncha C, Ph D, Donnelly AE, et al. Tracking of Physical Activity and Sedentary Behavior From Adolescence to Young Adulthood: A Systematic Literature Review. J Adolesc Heal [Internet]. 2019;65(4):446-54. Available from:

https://doi.org/10.1016/j.jadohealth.2019.03.013

8. Stalsberg R, Pedersen A V. Effects of socioeconomic status on the physical activity in adolescents: a systematic review of the evidence. Scand J Med Sci Sport. 2010;368-83.

9. Kahn JA, H MP, Huang B, Ph D, Gillman MW, M S, et al. Patterns and Determinants of Physical Activity in U. S. Adolescents. J Adolesc Heal. 2008;42:369-77.

10. Golden SD, Earp JAL. Social Ecological Approaches to Individuals and Their Contexts: Twenty Years of Health Education \& Behavior Health Promotion Interventions. Heal Educ Behav. 2012;39(3).

11. Langille JD, Rodgers WM. Exploring the Influence of a Social Ecological Model on School-Based Physical Activity. Heal Educ Behav. 2010;37(6):879-94.

12. Trost SG, Pate RR, Sallis JF, Freedson PS, Taylor WC, Dowda M, et al. Age and gender differences in objectively measured physical activity in youth. Med Sci Sport Exerc. 2002;34(2):350-5.

13. Lammle L, Worth A, Bos K. Socio-demographic correlates of physical activity and physical fitness in German children and adolescents. Eur J Public Heal. 2012;22(6):880-4.

14. Pate RR, Heath GW, Dowda M. Associations between Physical Activity and Other Health Behaviors in a Representative Sample of US Adolescents. Am J Public Heal. 1996;86(11).

15. Männikkö N, Billieux J, Kääriäinen M. Problematic digital gaming behavior and its relation to the psychological, social and physical health of Finnish adolescents and young adults. J Behav Addict. 2015;4(4):281-8.

16. Buda G, Sal L. Possible Effects of Social Media Use on Adolescent Health Behaviors and Perceptions. Psychol Rep. 2020;

17. Brodersen NH, Ph D, Steptoe A, Phil D, Williamson S, Wardle J, et al. Sociodemographic, Developmental, Environmental, and Psychological Correlates of Physical Activity and Sedentary Behavior at Age 11 to 12. Ann Behav Med. 2005;29(1):2-11.

18. Mendonça G, Cheng L, Melo E, Cazuza De Farias J. Physical activity and social support in adolescents: a systematic review. Heal Educ Q. 2014;29(5):822-39.

19. Beets MW, Cardinal BJ, Alderman BL. Parental Social Support and the Physical Activity - Related Behaviors of Youth: A Review. Heal Educ Behav. 2010;37(October):621-44. 
20. Mota J, Ph D, Almeida M, Santos P, Ph D, Ribeiro C, et al. Perceived Neighborhood Environments and physical activity in adolescents. Prev Med (Baltim). 2005;41:834-6.

21. Carroll-scott A, Gilstad-hayden K, Rosenthal L, Peters SM, Mccaslin C, Joyce R, et al. Disentangling neighborhood contextual associations with child body mass index, diet, and physical activity : The role of built, socioeconomic, and social environments. Soc Sci Med [Internet]. 2020;95(2013):10614. Available from: http://dx.doi.org/10.1016/j.socscimed.2013.04.003

22. Bauer GR. Incorporating intersectionality theory into population health research methodology: Challenges and the potential to advance health equity. Soc Sci Med. 2014;110:10-7.

23. Abichahine H, Veenstra G. Inter-categorical intersectionality and leisure-based physical activity in Canada. Heal Promot Int. 2017;32(March 2016):691-701.

24. Butt J, Weinberg RS, Breckon JD, Claytor RP. Adolescent Physical Activity Participation and Motivational Determinants Across Gender, Age, and Race. J Phys Act Heal. 2011;1074-83.

25. Babey SH, Hastert TA, Hongjian Y, Brown ER. Physical Activity Among Adolescents When Do Parks Matter? Am J Prev Med. 2008;34(4):345-8.

26. Jekauc D, Reimers AK, Wagner MO, Woll A. Prevalence and socio-demographic correlates of the compliance with the physical activity guidelines in children and adolescents in Germany. BMC Public Health [Internet]. 2012;12:714. Available from: http://www.embase.com/search/results? subaction=viewrecord\&from=export\&id=L366399611

27. Quon EC, Mcgrath JJ. Subjective Socioeconomic Status and Adolescent Health: A Meta-Analysis. Heal Psychol. 2014;33(5):433-47.

28. Leslie E, Kremer P, Toumbourou JW, Williams JW. Gender differences in personal, social and environmental influences on active travel to and from school for Australian adolescents. J Sci Med Sport [Internet]. 2010;13(6):597-601. Available from: http://dx.doi.org/10.1016/j.jsams.2010.04.004

29. GGD (Municipal and Regional Health Service), Centraal Bureau voor de Statistiek (CBS), RIVM. Gezondheidsmonitor Jeugd (Health Monitor Youth) [Internet]. 2015. Available from: https://www.volksgezondheidenzorg.info/onderwerp/gezondheidsmonitor-jeugd/inleiding

30. Toren SJ Van Den, Grieken A Van, Raat H. Associations of socio-demographic absenteeism, and substance use with recreational nitrous oxide use among adolescents : A cross-sectional study. PLoS One [Internet]. 2021;16(2):1-14. Available from: http://dx.doi.org/10.1371/journal.pone.0247230

31. Bergen D Van, Looijmans M, Balt E, Id SR, Domburgh L Van, Nauta M, et al. A multi-method psychological autopsy study on youth suicides in the Netherlands in 2017: Feasibility, main outcomes, and recommendations. PLoS One. 2020;(1):1-19.

32. Prochaska JJ, Sallis JF, Long B. A Physical Activity Screening Measure for Use With Adolescents in Primary Care. JAMA Pediatr. 2001;155(May):554-9.

33. Murphy $\mathrm{MH}$, Rowe DA, Belton S, Woods CB. Validity of a two-item physical activity questionnaire for assessing attainment of physical activity guidelines in youth. BMC Public Health [Internet]. 2015;18. Available from: http://dx.doi.org/10.1186/s12889-015-2418-6 
34. Martens MK, Assema P Van, Paulussen TGWM, Breukelen G Van, Brug J. Krachtvoer: effect evaluation of a Dutch healthful diet promotion curriculum for lower vocational schools. Public Heal Nutr. 2007;11(3):271-8.

35. Meerkerk G, Ph D, Eijnden RJJM Van Den, Ph D. The Compulsive Internet Use Scale (CIUS): Some Psychometric Properties. Cyberpsychol Behav. 2009;12(1).

36. Lemmens JS, Valkenburg PM, Peter J. Development and Validation of a Game Addiction Scale for Adolescents Development and Validation of a Game. Media Psychol. 2009;3269.

37. Rooij AJ Van, Schoenmakers TM. IVO Factsheet: Monitor Internet en Jongeren 2010-2012. Het (mobiele) gebruik van sociale media en games door jongeren. 2013;

38. Bacak V, Ólafsdóttir S. Gender and validity of self-rated health in nineteen European countries. Scand J Public Heal. 2017;(August 2016):1-7.

39. DeSalvo KB, Bloser N, Reynolds K, He J, Muntner P. Mortality Prediction with a Single General SelfRated Health Question. J Gen Intern Med. 2005;(1):267-75.

40. Ravens-sieberer U, Gosch A, Rajmil L, Erhart M, Bruil J, Power M, et al. The KIDSCREEN-52 Quality of Life Measure for Children and Adolescents: Psychometric Results from a Cross-Cultural Survey in 13 European Countries. Value Heal [Internet]. 2008;11(4):645-58. Available from: http://dx.doi.org/10.1111/j.1524-4733.2007.00291.x

41. Robitail S, D M, Simeoni M, Ph D, Erhart M, Sc M, et al. Validation of the European Proxy KIDSCREEN52 Pilot Test Health- Related Quality of Life Questionnaire: First Results. J Adolesc Heal. 2006;39.

42. The KIDSCREEN Group. The KIDSCREEN questionnaires Quality of life questionnaires for children and adolescents - Handbook -. 2006.

43. Cerin E, Leslie E. How socio-economic status contributes to participation in leisure-time physical activity. Soc Sci Med. 2008;66.

44. Vilhjalmsson R, Kristjansdottir G. Gender differences in physical activity in older children and adolescents: the central role of organized sport. Soc Sci Med. 2003;56:363-74.

45. Romaguera-bosch D, Tauler-riera P, Moreno-go C, Bennasar-veny M, Pericas-beltran J, Martinezandreu S. Clustering of lifestyle factors in Spanish university students: the relationship between smoking, alcohol consumption, physical activity and diet quality. Public Heal Nutr. 2012;15(May 2021):2131-9.

46. Mata J, Silva MN, Vieira PN, Carrac E V, Andrade AM, Sardinha LB, et al. Motivational "Spill-Over" During Weight Control: Increased Self-Determination and Exercise Intrinsic Motivation Predict Eating Self-Regulation. Heal Psychol. 2009;1-8.

47. Craggs C, Corder K, Sluijs EMF Van, Griffin SJ. Determinants of Change in Physical Activity in Children and Adolescents. Am J Prev Med [Internet]. 2011;40(6):645-58. Available from: http://dx.doi.org/10.1016/j.amepre.2011.02.025

48. Wills TA, Isasi CR, Mendoza D, Ainette MG. Self-Control Constructs Related to Measures of Dietary Intake and Physical Activity in Adolescents. J Adolesc Heal. 2007;41:551-8. 
49. Park H, Kim N. Predicting Factors of Physical Activity in Adolescents: A Systematic Review. Asian Nurs Res (Korean Soc Nurs Sci) [Internet]. 2008;2(2):113-28. Available from: http://dx.doi.org/10.1016/S1976-1317(08)60035-3

50. Matthews J, Moran A. Physical Activity and Self-regulation Strategy Use in Adolescents. Am J Heal Behav. 2011;35(6):9-11.

51. Anderson ES, Winett RA, Wojcik JR. Self-Regulation, Self-Efficacy, Outcome Expectations, and Social Support : Social Cognitive Theory and Nutrition Behavior. Ann Behav Med. 2007;34(3):304-12.

52. Woodruff SI, Conway TL, Edwards CC. Sociodemographic and smoking-related psychosocial predictors of smoking behavior change among high school smokers. Addict Behav. 2008;33:354-8.

53. Wills TA, Walker C, Mendoza D, Ainette MG. Behavioral and Emotional Self-Control: Relations to Substance Use in Samples of Middle and High School Students. Psychol Addict Behav. 2006;20(3):265-78.

54. Busch V, Manders LA, Rob J, Leeuw J De. Screen Time Associated with Health Behaviors and Outcomes in Adolescents. Am J Heal Behav. 2013;37(6):819-30.

55. Smyth JM. Beyond Self-Selection in Video Game Play: An Experimental Examination of the Consequences of Massively Multiplayer Online Role-Playing Game Play. Cyberpsychol Behav. 2007;10(5):717-21.

56. Mérelle SYM, Kleiboer AM, Schotanus M, Cluitmans TLM, Waardenburg CM. Present study Problematic video-gaming Method Participants and procedures. Clin Neuropsyciatry. 2017;11-9.

57. Granger E, Nardo F Di, Harrison A, Patterson L, Holmes R, Verma A. A systematic review of the relationship of physical activity and health status in adolescents. Eur J Public Heal. 2017;27(March):100-6.

58. Anderson-bill ES, Winett RA, Wojcik JR. Social Cognitive Determinants of Nutrition and Physical Activity Among Web-Health Users Enrolling in an Online Intervention: The Influence of Social Support, Self-Efficacy, Outcome Expectations, and Self-Regulation. J Med Internet Res. 2011;13:1-16.

59. Franzini L, Elliott MN, Cuccaro P, Schuster M, Gilliland MJ, Grunbaum JA. Influences of Physical and Social Neighborhood Environments on Children 's Physical Activity and Obesity. Am J Public Heal. 2009;99(2):271-8.

60. Cradock AL, Kawachi I, Colditz GA, Gortmaker SL, Buka SL. Social Science \& Medicine Neighborhood social cohesion and youth participation in physical activity in Chicago. Soc Sci Med [Internet]. 2009;68(3):427-35. Available from: http://dx.doi.org/10.1016/j.socscimed.2008.10.028

61. Smith KP, Christakis NA. Social Networks and Health. Annu Rev Sociol. 2008;

62. Thoits PA. Mechanisms Linking Social Ties and Support to Physical and Mental Health. J Heal Soc Behav. 2011;52(2).

63. Hankivsky O, Kapilashrami A. Intersectionality and why it matters to global health. Lancet. 2018;391:2589-91. 
64. Chafetz JS. Feminist Theory and Sociology: Underutilized Contributions for Mainstream. Annu Rev Sociol. 1997;23:97-120.

65. Wills TA, Stoolmiller M. The Role of Self-Control in Early Escalation of Substance Use: A TimeVarying Analysis. J Consult Clin Psychol. 2002;70(4):986-97.

66. Hill M, Sternberg A, Suk WH, Meier MH, Chassin L. The Intergenerational Transmission of Cannabis Use: Associations between Parental History of Cannabis Use and Cannabis Use Disorder, Low Positive Parenting, and Offspring Cannabis Use. Psychol Addict Behav. 2019;32(1):93-103.

67. Dvorak RD, Day AM. Addictive Behaviors Marijuana and self-regulation: Examining likelihood and intensity of use and problems. Addict Behav [Internet]. 2014;39(3):709-12. Available from: http://dx.doi.org/10.1016/j.addbeh.2013.11.001

68. Junger $M$, Kampen $M$ Van. Cognitive ability and self-control in relation to dietary habits, physical activity and bodyweight in adolescents. Int J Behav Nutr Phys Act. 2010;7(22).

69. Agyemang C, Denktas S, Bruijnzeels M, Foets M. Validity of the single-item question on self-rated health status in first generation Turkish and Moroccans versus native Dutch in the Netherlands. Public Health. 2006;120:543-50.

70. Centraal Bureau voor de Statistiek (CBS). Jaarrapport Integratie (Yearly Report on Integration) 2020 [Internet]. 2020 [cited 2021 May 5]. Available from: Centraal Bureau voor de Statistiek

71. Brockman R, Jago R, Fox KR, Thompson JL, Cartwright K, Page AS. " Get off the sofa and go and play ": Family and socioeconomic influences on the physical activity of 10-11 year old children. BMC Public Health. 2009;7:3-9.

72. Edwardson CL, Gorely T, Musson H, Duncombe R, Sandford R. Does activity-related social support differ by characteristics of the adolescent? J Phys Act Heal [Internet]. 2014;11(3):574-80. Available from: http://www.embase.com/search/results?

subaction=viewrecord\&from $=$ export\&id $=\mathrm{L} 1372835734$

73. Assari S, Caldwell CH, Zimmerman MA. Perceived Neighborhood Safety During Adolescence Predicts Subsequent Deterioration of Subjective Health Two Decades Later; Gender Differences in a RaciallyDiverse Sample. Int J Prev Med. 2015;6.

74. Chinapaw MJM, Mokkink LB, Poppel MNM Van, Mechelen W Van, Terwee CB. Physical Activity Questionnaires for Youth A Systematic Review of Measurement Properties. Sport Med. 2010;40(May 2009):539-63.

75. Sallis JF, Saelens BE. Assessment of Physical Activity by Self-Report: Status, Limitations, and Future Directions. Res Q Exerc Sport. 2015;(July).

\section{Figures}




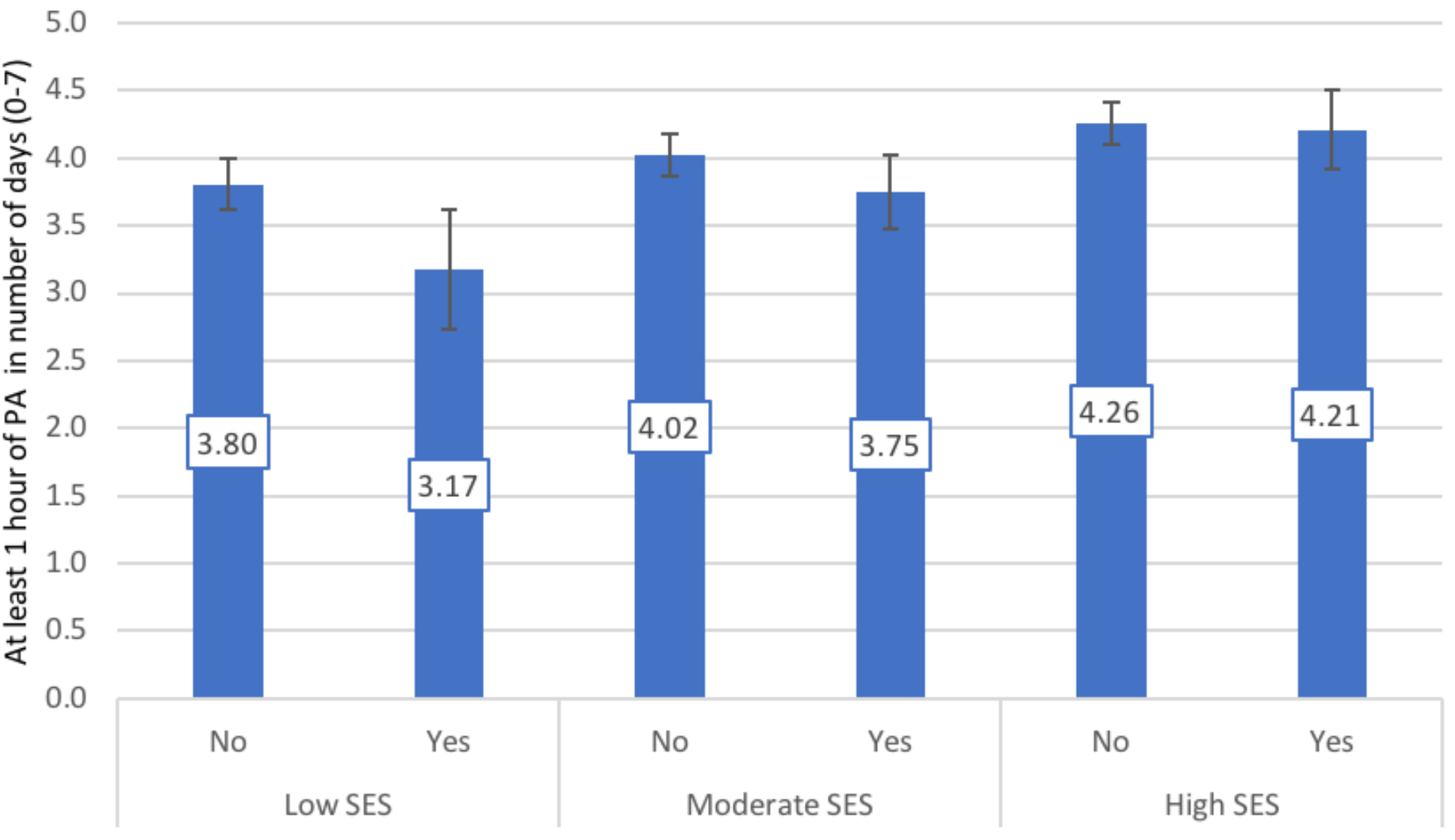

Figure 1

Predicted mean fixed scores of PA by cannabis use in the last 4 weeks stratified by family SES, with $95 \%$ $\mathrm{Cl}$

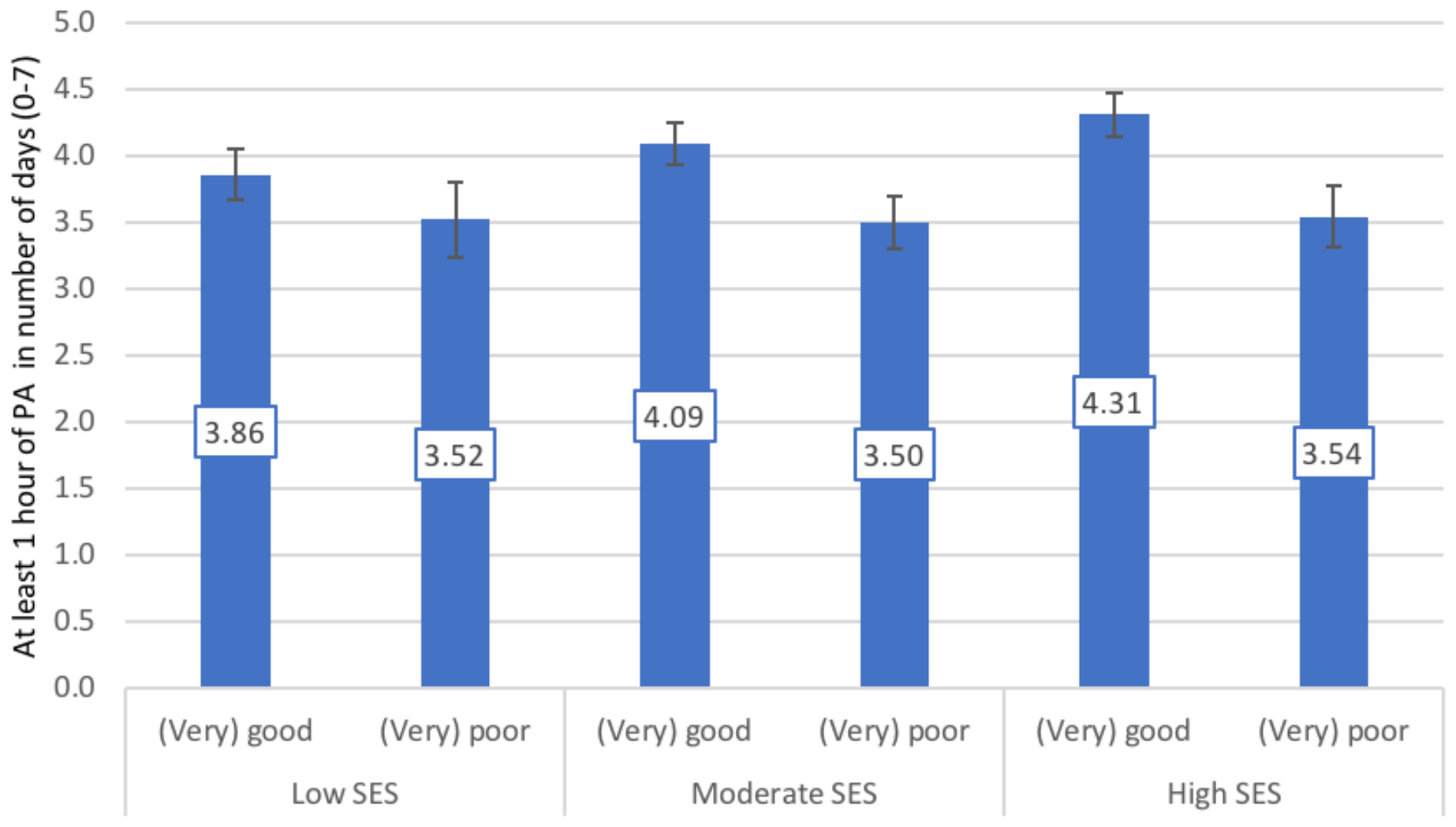


Figure 2

Predicted mean fixed scores of PA by self-perceived health stratified by family SES, with $95 \% \mathrm{Cl}$ 